\title{
Response of Single and Grouped Pile Subjected To Lateral Load In Cohesionless Soil
}

\author{
Mahdy Khari ${ }^{1 a^{*}}$, Khairul Anuar Kassim ${ }^{2 b}$, Payman Alimohammadi ${ }^{3 c}$ \\ 1,2,3 Department of Geotechnics and Transportation, Faculty of Civil Engineering, \\ Universiti Teknologi Malaysia, Skudai 81300, Johor Bahru, Malaysia \\ E-mails:1'mehdikhari@gmail.com ;2kanuar@utm.my ; ${ }^{3}$ payman_alimohamadi@yahoo.com
}

Keywords: Single pile, Lateral Load, Mobile pluviator, Group pile, Relative density, Cohesionless soil.

\begin{abstract}
Piles are generally required to transfer load from a superstructure through weak or compressible strata, or through water, on to stiffer and less compressible soils and rock. The pile behavior is very important in Soil-Pile interaction (as known Kinematic Interaction) so that grouped and single pile behavior differs owing to the impacts of the pile-to-pile interaction. In this research presents a series of experimental investigations carried out on single and group pile subjected to monotonic lateral loadings. The aluminum model piles were tested in the different relative densities in Johor Bahru sand. The sand samples were prepared by using the newly designed Mobile Pluviator adopted the air pluviation method. The different configurations of model pile groups for embedded length-to-diameter ratio equal to 32 into loose and dense sand spacing from 3 to 6 pile diameter (D) were conducted. The ultimate lateral load is increased $53 \%$ in increasing of s/d from 3 to 6 owing to effects of sand relative density. A ratio of s/D more than $6 \mathrm{~d}$ is large enough to eliminate the pile-to-pile interaction and the group effects. It may be more in the loose sand.
\end{abstract}

\section{Introduction}

Pile foundations provide support for superstructures, transferring their load to layers of soil that have sufficient bearing capacity. Determining the soil resistance against the movement of laterally loaded piles is a challenging task for geotechnical engineers. Several methods for analysis of the pile and soil resistance have been proposed in the literature[1-3]. To evaluate the single and grouped piles behavior, several methods has developed by investigators in numerical such as Beam on Nonlinear Winkler Foundation (BNWF) $[4,5]$. In addition, the estimations of ultimate lateral resistance and lateral subgrade modulus within a pile group are known as they are the key parameters in the soil-pile interaction phenomenon, however, the predictions of existing numerical methods to determine these parameters are often different $[3,4,6]$. Therefore, this study presented a series of tests to fill this gap through a comprehensive experimental investigation into the single and grouped pile behavior.

\section{Test Set up and Procedures}

Fig. 1 shows the schematic diagram of the tests. The soil tank used in this research was a rectangular box with dimensions of $900 \times 700 \times 65 \mathrm{~mm}$. The lateral load was applied to the model pile using dead weights placed on a loading pan connected to a flexible steel wire, strung over a pulley supported by a loading platform.

The model pile was closed-end and hollow circular section fabricated from aluminum alloy tubes $\left(E_{p}=69.8 \mathrm{GPa}\right)$ of $15.88 \mathrm{~mm}$ out diameter, 1 mmwall thickness and an embedded depth of $500 \mathrm{~mm}$. It is worth noting that, for the pile properties and the selected soil, pile behaves as flexible pile.

The tests were conducted in dried sand (in the laboratory temperature) from Johor Bahru sand. The sampled sand was classified as SP, according to the Unified Soil Classification System (USCS). The, medium diameter $\left(D_{50}\right)$ and uniformity coefficient $\left(C_{u}\right)$ of sand were 0.532 and $0.17 \mathrm{~mm}$, 
respectively, and particle sizes in a range of $0.075-0.97 \mathrm{~mm}$. Based on a standard density test, minimum and maximum unit weights of sand were $13.74 \mathrm{kN} / \mathrm{m}^{3}$ and $16.38 \mathrm{kN} / \mathrm{m}^{3}$.

The single pile instrumented for measuring strain and bending moment during the tests. The two Linear Differential Transducer (LVDTs) used to measure the pile head's deflection. The seven gauges were attached along to the model pile shaft (Fig. 1). The instrumented sensors on the model pile were electric-resistance strain gages with resistance of $350 \Omega$.

To reconstruct the sand samples with different relative densities $\left(\mathrm{D}_{\mathrm{r}}\right)$ of $30 \%$ (loose) and $75 \%$ (dense), the newly designed Mobile Pluviator was designed. Detailed descriptions for the sand sample preparation using the Mobile Pluviator can be found in Khari et al.[7].

The soil tank was filled using the Mobile Pluviator based on the desirable relative density in each of the tests. The surface of the model ground was leveled so that the final height of the reconstructed samples was $650 \mathrm{~mm}$. At least 24 hours elapsed before applying any load to the model pile. Several tests conducted on single pile instrumented by the strain gauges. In addition, to determine the grouped piles behavior, different configuration of piles were carried out with the center-to-center spacing of piles equal to 3D and 6D (D-pile diameter) in loose and dense sandy soil. The lateral load was applied by about 10 gradually increments.

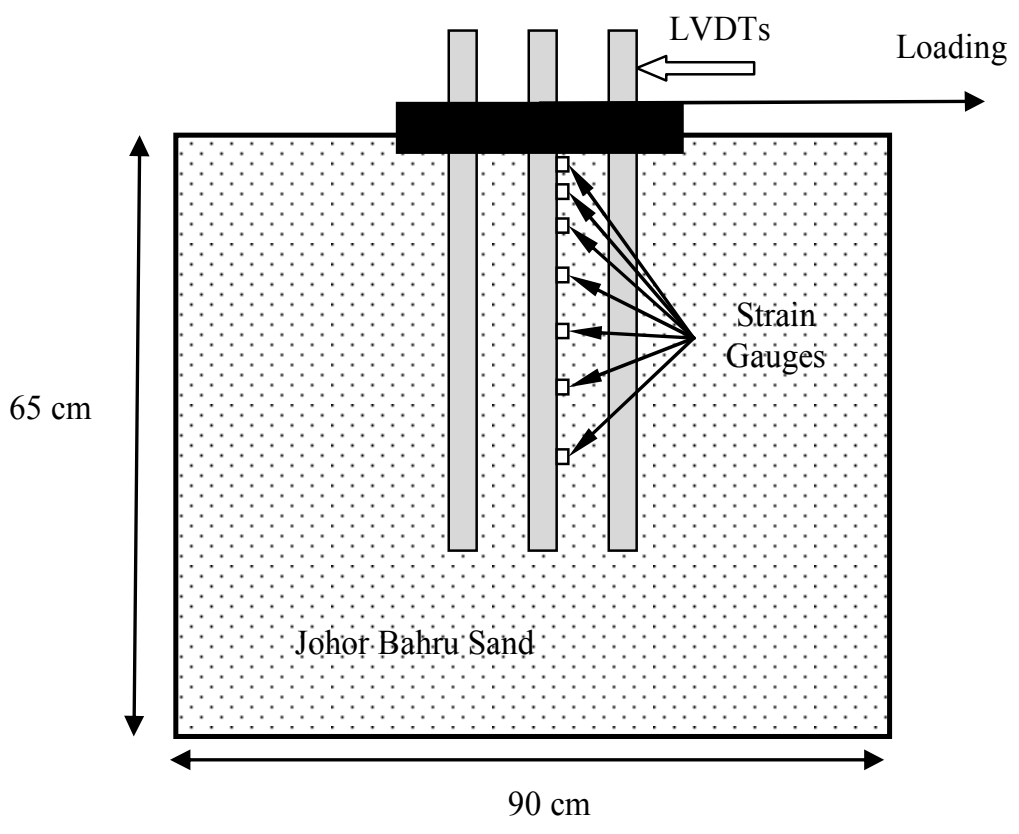

Fig. 1 Schematic View of Experimental Set up

\section{Experimental Results and Discussion}

The lateral load displacement curves for a single bored pile is shown in Fig. 2. The Fig. shows that for any given load, the lateral displacement was much higher than that of the vertical displacement. In addition, it can be seen from the Fig. that the horizontal displacement in loose sand was at least $70 \%$ higher than that in dense sand. Typical strain variation for the bored pile subjected to lateral loading is presented in Fig. 3. From the Fig., it can be stated that the strain variation has a trend similar in both loose and dense samples. However, the value of strain in dens sand was higher than that in loose sample because of the active length of the model pile. 


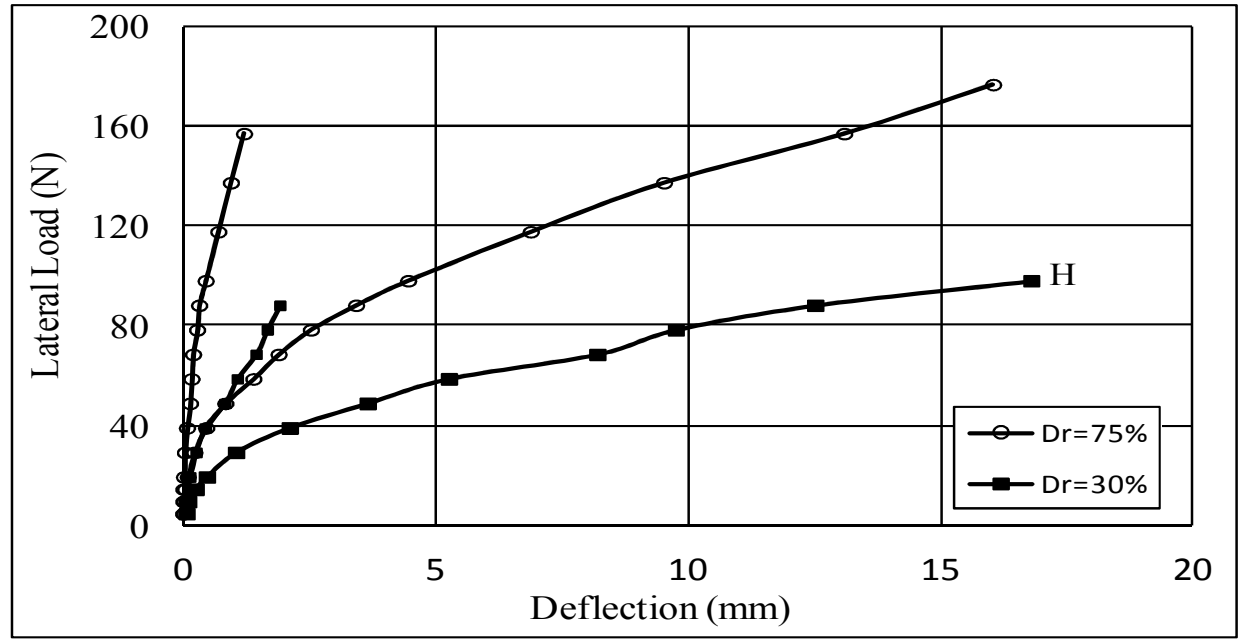

Fig. 2 Lateral load versus deflection diagram for single pile (Note: $\mathrm{H}=$ horizontal; $\mathrm{V}=$ vertical)
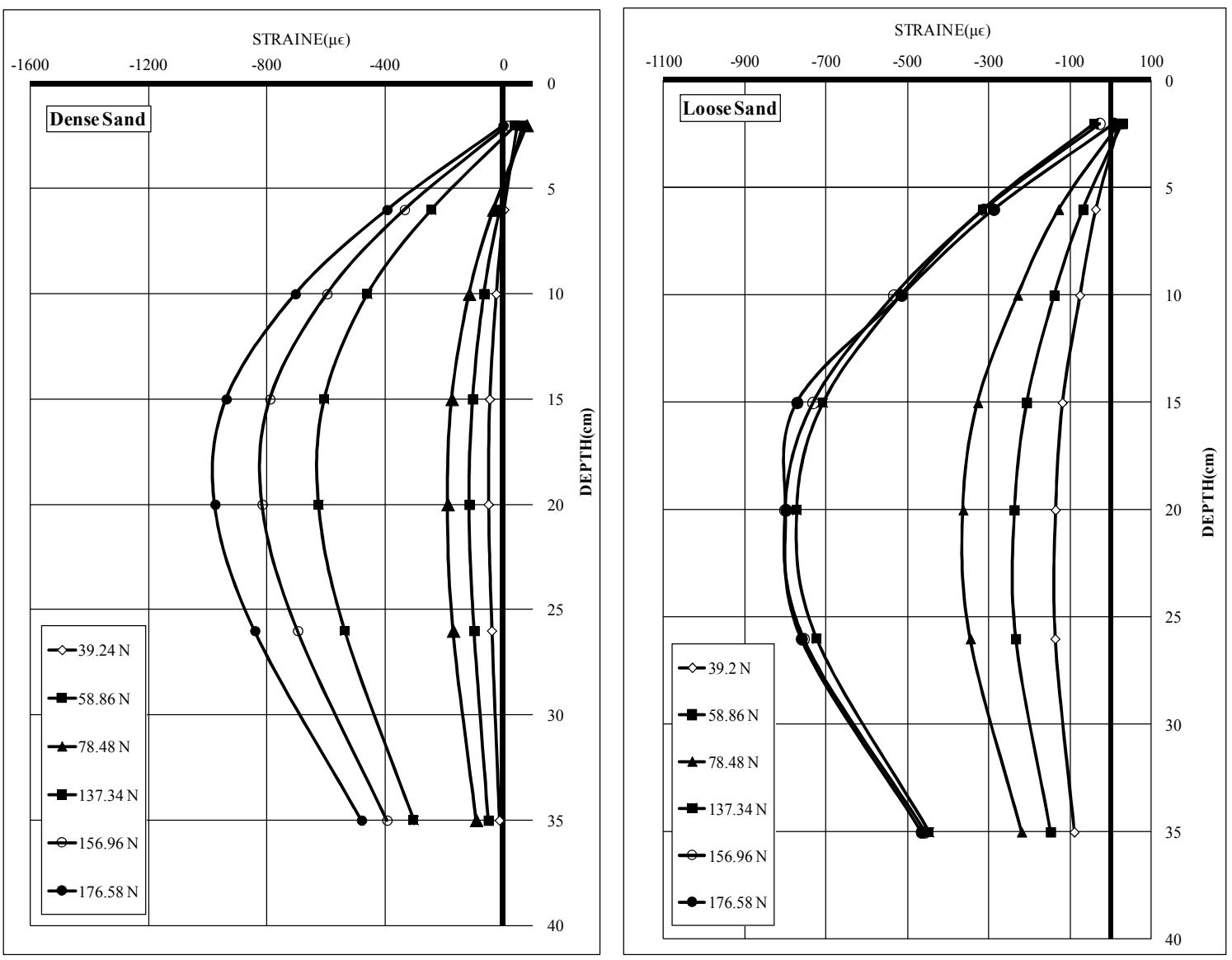

Fig. 3 Strain versus depth for single pile in loose and dense

The influence of the piles' spacing on the lateral deflection and group behavior for the $3 \times 3$ pile group with a square arrangement is shown in Fig. 4. For a particular value of lateral movement, the magnitude of lateral load decreased when the piles' spacing decreased in dense and loose sand. At the deflection of $0.1 \mathrm{D}$, the lateral load of the pile group was about 2.90 times higher than that of the single pile.

The ultimate lateral resistance in the different arrangements of pile groups was estimated by the load-deflection curves. The soil resistance to piles under lateral load may be involving of the side friction and the frontal normal reaction. However, these two reactions are dependent on shape factor 
taking in account nonuniform distribution of earth pressure in front of pile and lateral shear drag. There are several methods to estimate the ultimate lateral resistance such as double tangent and loglog method. In this study, the ultimate lateral resistance was taken as the load corresponding to the reference deflection of $0.2 \mathrm{D}$ on the load-deflection curves. The results obtained exhibit that the increasing rate of deflection was reached at about $0.2-0.35 \mathrm{D}$. The ultimate lateral load in single pile was about $25 \%$ of the ultimate load for $3 \times 3$ pile group with the pile spacing $=6 \mathrm{D}$ while this percentage for the spacing of $3 \mathrm{D}$ was about $47 \%$. In fact, with increasing of the pile spacing from $3 \mathrm{DD}$ to $6 \mathrm{D}$, the value of ultimate lateral load about $0.53 \%$ is increased.
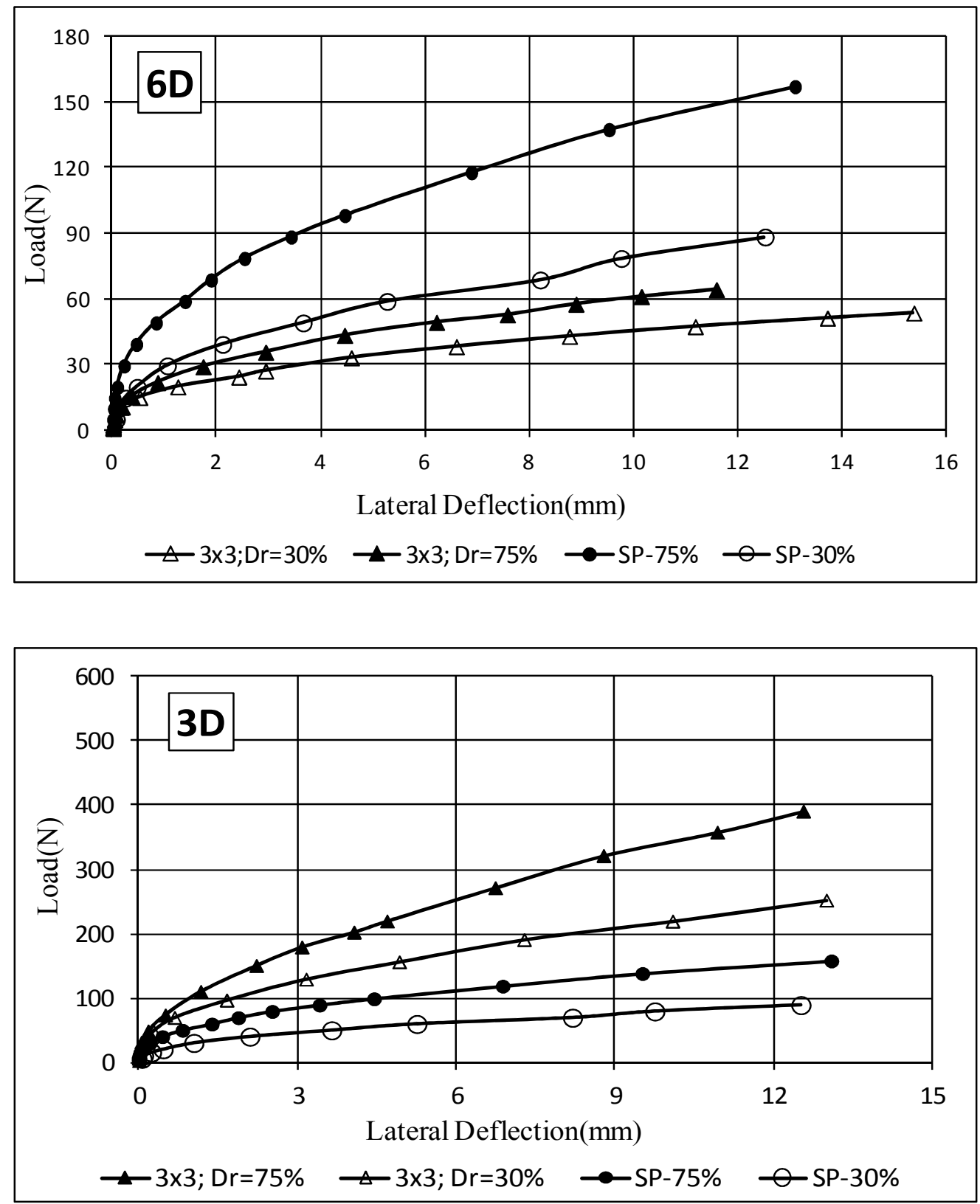

Fig. 4 Lateral load versus lateral deflection (3×3-pile group) 


\section{Conclusions}

The behavior of single pile and grouped is believed to be understood, especially for soils where the subgrade modulus is independent of time. Based on this demand, a series of tests were carried out on pile group under lateral static loading in sandy soils. Based on the results of present experiment, the load-deflection curves were estimated to determine the ultimate lateral resistance of group. The qualitative and quantitative effects of the relative density of the sand have been carried out. The ultimate lateral load was increased $53 \%$ in increasing of $s / \mathrm{D}$ from 3 to 6 . The subgrade modulus decreased with increasing deflection. Width and pile stiffness were two important factors effective on this decreasing. A ratio of $s / \mathrm{D}$ more than $6 \mathrm{D}$ was large enough to eliminate the pile-to-pile interaction and the group effects. It may be more in the loose sand.

\section{Acknowledgments}

The research was undertaken with support from research university Grant (no. Q.J130000.2513.03H63) under the University Teknologi Malaysia (UTM). The first author would like to thank the Ministry of Education (MOE) and the Research Management Center for the financial supports during this study.

\section{References}

[1] J.X. Zha and G. Gazetas: Nonlinear behavior of single piles vibrating vertically, in Geotechnical Special Publication, (2008) Sacramento, CA.

[2] M. Khari, A.K. Kassim, and A. Adnan: Dynamic Soil-Pile Interaction under Earthquake Events, in $A I C C E / G I Z^{\prime} 122012$ : Park Royal Penang Resort,Malaysia.

[3] M. Khari, A.K. Kassim, and A. Adnan: An Experimental Study on Pile Spacing Effects under Lateral Loading in Sand, The ScientificWorld Journal, (2013). 2013: p. 8.

[4] M. Khari, A.K. Kassim, and A. Adnan: Development of p-y Curves of laterally loaded piles in Cohesionless Soil, The Scientific World Journal, (2014). 2014: p. 8.

[5] M.H. El Naggar, et al.: Simplified BNWF model for nonlinear seismic response analysis of offshore piles with nonlinear input ground motion analysis, Canadian Geotechnical Journal, (2005) 42(2): p. 365-380.

[6] N. Patra, and P. Pise: Ultimate Lateral Resistance of Pile Groups in Sand, Journal of Geotechnical and Geoenvironmental Engineering, (2001) 127(6): p. 481-487.

[7] M. Khari, A.K. Kassim, and A. Adnan: Snad Sample Preparation Using Mobile Pluviator, Arabian Journal for Science and Engineering, (2014) 10.1007/s13369-014-1247-8. 